Send your letters to the editor, British Dental Journal, 64 Wimpole Street, London W1G 8YS or by email to bdj@bda.org

Priority will be given to letters less than 500 words long. Letters should be typed. Authors must sign the letter, which may be edited for reasons of space

\section{Selection procedures}

Sir, I read with interest a recent letter by M Crossley and M Smith (BDJ 2004, 196: 441) after their research into the public service values of dental students at Sheffield and comparing the results with Manchester dental students.

Several days later, I also came across an article in The Times entitled 'Class is the key to studying medicine' (Thursday 29 April 2004). In summary, it pointed out the biased nature of current selection procedures for entry into medical and dental schools, stating that $74 \%$ of admissions are comprised of students from the highest social classes.

Thus, I am curious as to whether the admissions procedures for the two dental schools differ and more importantly, does the background status of the students influence their attitude towards public services?

It may also be of relevance that the increase in financial debt incurred by students for long courses such as dentistry may have a significant bearing on their attitudes towards provision of public dental services.

J. Lai

Northampton

One of the authors of the paper, M Smith responds: I thank $J$ Lai for drawing my attention to The Times article.

Unfortunately our original line of enquiry did not investigate social status, simply motives for choice of a dental career.

A comparison of HEFCE performance indicator data for 2001 entrants to Manchester and Sheffield dental schools (for which I am indebted to their respective Policy and Planning Unit and Corporate Planning Office) suggests that differences between the two are small.

Manchester accepts 13\% more entrants from state schools or colleges, while Sheffield accepts 6\% more from lower social classes and non-HE participating backgrounds. It is unlikely that these alone would account for personal gain being rated less of a motivator for Sheffield students. Investigating possible links between motives for career choice and both class and student debt is an avenue of research that might inform the debates on widening access and dental education's modernisation agenda.

doi: 10.1038/sj.bdj.4811725

\section{Open co-operation}

Sir, I read with interest the letter from L McArdle (BDJ 2004, 197:114). However, the explanation of the reasons for the establishment of the British Association of Surgical Dentists, which has recently changed its name to the British Association of Oral Surgeons (BAOS), is misleading.

Since its foundation in 1962 the (original) BAOS, which changed its name to BAOMS in 1982 to reflect the widening scope and development of the specialty, has maintained an inclusive policy for all those providing clinical services and providing the academic base within the maxillofacial region.

This is reflected by the first Object of the Association to promote the advancement of education, research and the development of oral and maxillofacial surgery, oral surgery and surgical dentistry in the British Isles. In addition to specialists, membership has always been open to registered medical or dental practitioners in the British Isles or from overseas who are interested in these specialty areas.

This approach puts BAOMS in a unique position to provide leadership and coordinated advice across the whole specialty area for the benefit of our patients and all those involved in providing clinical care.

L McArdle refers to the recent views of the SDAC and the GDC. BAOMS supports the recommendation in the SDAC Report that the GDC should be invited to consider reconfiguration of the current arrangements for oral surgery (including academic oral surgery) and surgical dentistry. However, it seems premature to refer to the views of the GDC when the work of the (GDC) Specialist Lists Review Group is still at an early stage with a preliminary report only expected later this 
year. BAOMS welcomes any development which promotes high standards of practice within the maxillofacial region in its widest sense and is therefore reassured that the new BAOS will promote the highest ideals and standards for oral surgery and will maintain close links with other professional bodies.

BAOMS has already expressed the wish to work closely with the new association. Open co-operation fits well with the principle of the multidisciplinary team including oral and maxillofacial surgery, oral surgery and other dental and medical specialties integrated with primary care services. This is a concept strongly supported by BAOMS.

Further information about BAOMS can be obtained through the website: www.baoms.org.uk or through the BAOMS office e mail: office@baoms.org.uk.

\section{Barnard}

\section{London}

doi: 10.1038/sj.bdj.4811726

\section{Paternalism and tradition}

Sir, congratulations to J A Clewett ( $B D J$ 2004, 197: 113) for having the temerity to question the views of a group of Scottish anaesthetists Shearer et al (BDJ 2004, 196 : 93-98) that conscious sedation in dentistry should be their preferred domain.

May I respectfully add to his observations that although vested interests may have been a function in arriving at their conclusions, paternalism and tradition may also have been relevant.

Conscious sedation in dentistry has evolved and continues to evolve to suit the timely needs of both patient and dentist without compromise of standard.

As J A Clewett affirms "those of us who practice sedation need to firmly maintain our right to administer safely and to demonstrate our commitment to high standards of practice, training, clinical audit and continuing professional development'.
Common sense rather than vested interests would seem to be the key in this debate.

\section{J. P. Rosie}

Merseyside

doi: 10.1038/sj.bdj.4811727

\section{Tongue in cheek}

Sir, fill some of the tongue's space with a lower lingual acrylic 'placebo' splint, and what happens?

The tongue moves upwards and outwards to cover the occlusal surface of the teeth. Hey Presto! You have the ultimate biological 'soft' occlusal splint, reduced parafunction and surprise, surprise, reduction in TMD symptoms.

I don't think that I am ready, just yet, to accept that occlusion is a relatively unimportant factor influencing recovery in the majority of TMD patients seen in practice.

\section{Kirk}

Merseyside

doi: $10.1038 /$ sj.bdj.4811728

\section{Nut and tobacco chewing}

Sir, the habit of chewing areca nut with or without tobacco receives little attention, especially their toxic effect on hard tissues. People are switching over to smokeless tobacco and areca nut products due to the ban on smoking in public places.

The effects of areca nut chewing products on hard tissues are scanty or not available. We hypothesised that the hardness of areca nut and tobacco present in chewing products might have a role in the causation of dental attrition and sensitivity.

Thus we have randomly collected the data on attrition and sensitivity of the 169 subjects ( 123 chewers and 46 nonchewers) attending Government Dental College, Ahmedabad, India. The data was analysed using the Chi square test.

The result suggests that areca nut and tobacco chewing are having adverse effects on teeth as a significantly higher percentage of attrition was observed among chewers as compared to nonchewers.

Further analysis of data on the basis of different chewing habits indicated no significant difference in the number of attrition cases between maya (containing areca nut, lime and tobacco), gutkha (consisting of areca nut, catechu, lime, cardamom and unspecified flavouring agents) and mixed (gutkha, maya, pan, tobacco, arecanut) chewers.

Sensitivity towards cold beverages was also significantly higher among the chewers in comparison to non-chewers. Collaert and Fischer reported that local pulpal inflammation, traumatic oral hygiene and dietary habits have been considered in the etiology of dentine hypersensitivity ${ }^{1}$.

They also suggested that dentine hypersensitivity is probably caused by a change in fluid flow in the dentinal tubules, which in turn excited the nerve endings located at the pulpdentine border.

The higher sensitivity towards cold foodstuffs could be attributed to excessive load on mastication on the teeth due to the chewing of tobacco and areca nut. These chewing materials might have affected indirectly (excessive load of mastication of chewing material on teeth) the enamel layer covering the dentinal tubules and caused adverse effects on the tubules structure and function. The duration of habits did not show any definite trend, which indicates that some other natural factors such as ageing, structure of tooth etc. might also be responsible along with chewing habits for attrition and sensitivity.

Excessive abrasion of the incisal and occlusal surfaces of the maxillary and mandibular teeth might occur with the habitual use of coarse, abrasive chewing tobacco or cigars as suggested by Christen $^{2}$. Bowles et al found insoluble particulate matter about $0.5 \%$ of the dry weight of average tobacco samples ${ }^{3}$.

The insoluble particulate matter of tobacco might be one of the underlying causes of higher attrition along with other factors such as the hardness of the areca nut, increased load of mastication on tooth due to chewing etc. The data suggest that areca nut and tobacco chewing are responsible for higher dental attrition and sensitivity. However, the data should be interpreted with caution for the general population as the subjects attended the hospital for some dental problem. Further, studies are in progress to substantiate these results.

\section{S. Kumar \\ G. Parmar \\ H. N. Saiyed}

doi: 10.1038/sj.bdj.4811729

1. Collaert B, Fischer C Dentine hypersensitivity: a review. Endod Dent Traumatol 1991; 7:145-152. 2. Christen Arde G. The clinical effects of tobacco on oral tissue. JAm Dent Assoc 1970; 81: 1378-1382. Bowles William H, Wilkinson Mitchell R, Wagner Martin J, Woddy Ronald D. Abrasive factor in denta attrition. JAm Dent Assoc 1995; 126: 327-331. 